\title{
OBJETOS IDEALES Y ENTES METAFÍSICOS EN LA OBRA DE JOSÉ GAOS
}

CARLos Llano Cifuentes

UNIVERSIDAD PANAMERICANA

\section{Introducción}

Es difícil elegir en la extensa obra de José Gaos el eje central de su filosofía, que al final de su vida, sin embargo, se configuró como el cuerpo coherente, si no sistemático, de un profundo pensamiento propio. Español trasterrado en México, como se calificaba a sí mismo, por causa de la Guerra Civil Española de los años treinta, se preciaba de ser discípulo predilecto, y lo fue efectivamente, de José Ortega y Gasset; y expuso durante muchos años sus vastos conocimientos filosóficos, más amplios y rigurosos que los de Ortega a nuestro juicio, en la Universidad de México.

El hecho de que la mayor parte de sus lecciones se encuentre aún inédita es un obstáculo más para esa elección. Pero el respeto a la metafísica y, simultáneamente, su aproximación fenomenológica $-\mathrm{y}$, por tanto, no definitiva - ante sus problemas capitales, pueden contarse sin duda entre los hitos más señalados de su filosofía, y parte importante de la herencia o huella firme dejada por él en la cultura intelectual de México.

Uno de los puntos representativos de ese respeto y postura suya ante los grandes temas de la metafísica es el del presente estudio, que se limita a lo que sobre los objetos ideales y los entes metafísicos ha escrito en $\mathrm{Del}$ hombre. ${ }^{1}$

1 José Gaos, Del hombre, UNAM, México, 1992, 587 pp., su último libro publicado, que recoge los apuntes para su curso en la Universidad Nacional Autónoma de México en 1965. Las primeras 27 lecciones (la lección XXVII se refiere precisamente a los objetos metafísicos) fueron escritas y revisadas por el autor inmediatamente antes de que le sobreviniera la muerte repentina en pleno trabajo de cátedra. Las restantes, hasta la lección XIVIII, que es la última, fueron revisadas, con base en sus mismos apuntes, por dos discípulos suyos, Fernando Salmerón y Elsa Frost, con una estrecha fidelidad al pensamiento y letra de su maestro. Estamos, por tanto, en Del hombre ante las últimas (y a nuestro juicio las más importantes) concepciones filosóficas de nuestro autor.

Del hombre trasciende el ámbito antropológico que su título sugeriría. No se trata sólo de una antropología filosófica, ni aun de una antropología trascendental, sino de una metafísica muy peculiar elaborada a partir del fenómeno humano. 


\section{Apertura metafisica}

El método seguido por Gaos aquí es el de la fenomenología, personalmente interpretada. Cómo puede hacerse metafísica con un método tal -y si puede hacerse- es algo que no discutiremos ahora pues requeriría la prueba de la obra misma. Nos limitaremos a consignar que el método seguido en su filosofía última es expresamente fenomenológico, a tal punto que el autor lo utiliza y deja ver cómo lo utiliza cuando lo hace.

Sin embargo, se trata de una fenomenología abierta y atenta a los grandes problemas metafísicos. Aunque esta apertura no baste por sí sola para el acceso epistemológico al ente metafísico entraña una seria y reiterada preocupación por el tema. La obra de Gaos constituye así una clarificación de la metafísica por la vía de la duda, o, más rigurosamente, un intento metafísico a partir de la fenomenología, sin caer en la paradoja de una fenomenología metafísica.

Hay fenómenos del ser humano estudiados por Gaos que nos levantan por encima del mero nivel fenoménico de ellos, ya que apuntan hacia conceptos que no admitirían de suyo un tratamiento fenomenológico, porque la existencia de sus correspondientes objetos requeriría raciocinios en linderos allende la experiencia. Pero Gaos no considera en principio como ilegítimos tales raciocinios (sólo los calificará de insuficientes). ${ }^{2}$

Más aún, en el caso de que tales razonamientos sobre los objetos de conceptos metafísicos pensados a partir de fenómenos fueran inválidos desde un punto de vista lógico, no por ello habría de negarse la existencia de tales objetos. Recogemos aquí el breve diálogo con uno de sus alumnos, tal como se relata en Del hombre:

-Estos conceptos [metafísicos] [... ] los pensamos como conclusiones de raciocinios cuyas premisas enuncian fenómenos [... ], o bien pensamos los conceptos de los objetos metafísicos como postulados de que deducimos teoremas que enuncian fenómenos. Ejemplos [...] si y sólo si hay átomos, entonces las combinaciones químicas; sí y sólo si hay almas sustanciales, entonces la identidad del yo; si y sólo si hay Dios, entonces hay seres contingentes [...]

-Pero si tales raciocinios fueran lógicamente inválidos, los objetos metafísicos no existirían.

-No. No es lógicamente válido inferir de la invalidez lógica de un raciocinio de existencia la inexistencia, que podrá conocer por otro raciocinio válido o conocerse por otra vía (p. 123).

A pesar del eco kantiano de este último recurso a "otra vía", Gaos deja abierta la posibilidad del conocimiento racional de la existencia de objetos

2 Del hombre, ed. cit., p. 418. 
metafísicos, aunque no puedan éstos presentarse fenoménicamente, y aunque ciertos raciocinios hechos a partir de los fenómenos correspondientes (combinaciones químicas a partir de las que se conoce la existencia de los átomos; identidad del yo a partir de la que se conoce la existencia de almas sustanciales; la existencia de seres contingentes a partir de la cual se conoce la existencia de Dios... ) pudieran ser inválidos para alguien en determinados cánones lógicos.

En esta apertura al problema metafísico Gaos se encara con el positivismo lógico, para el que los conceptos metafísicos carecerían de sentido (p. 269). Según Gaos, tanto Dios como el espíritu puro son perfectamente pensables (p. 196), lo cual no le impide sugerir que las proposiciones metafísicas no objetivan nada (p. 269). Pese a esto, no sólo no carecen de sentido, sino que se acreditan reiterativamente como ilustrativas del ser humano, pues son "concepciones humanas reveladoras de quien las piensa" (p. 536). ${ }^{3}$

\section{Expresión, imagen y pensamiento}

Como se sabe, la posibilidad de la metafísica queda cerrada cuando el pensamiento se reduce a la expresión verbal o a la imagen, ya que los entes metafísicos son inimaginables, y, en cierto modo, inefables, al menos porque implican ser más de lo que de ellos puede hablarse.

En los primeros pasos de su fenomenología, y antes de abordar la cuestión que nos ocupará acerca de los objetos ideales y los entes metafísicos, Gaos hace una fuerte distinción entre la palabra, la imagen sensible y el pensamiento cuyas fronteras han quedado abatidas por los máximos adversarios de la metafísica tal como se han dado en la historia: los empiristas, al modo de Hume, confundiendo el pensamiento con la imagen sensible, y los neopositivistas lógicos, identificando el pensamiento con el lenguaje.

Para diferenciar el concepto intelectual de la imagen, recurre Gaos fenomenológicamente a las dos pruebas de James. Primero, la de las existencias separadas: cuando dos realidades existen separadamente, son distintas (si todos y sólo los hielos fueran fríos no distinguiriamos el hielo del frío); y segundo, la de la modulación diversamente definida. ${ }^{4}$

${ }^{3}$ Gaos evita una confrontación global con el positivismo lógico, la cual se encuentra no obstante implicada en su doctrina. Según nuestro autor, el positivismo lógico considera sin sentido las proposiciones metafísicas porque quedan incluidos en ellas los sentimientos subjetivos o emociones del que las enuncia. Pero en las coordenadas filosóficas de Gaos toda proposición no sólo designa los objetos sino que al mismo tiempo significa las emociones o estados de ánimo del sujeto designante, respecto del objeto designado, incluso en las aparentemente frías proposiciones científicas (p. 73 ss.). Y esto, en las coordenadas del positivismo lógico, supondría que toda proposición, y no sólo las metafísicas, carecería de sentido.

4 Nosotros diríamos que se trata más bien de las pruebas de Francis Bacon en su Novum Organum: tablas de ausencia, tablas de presencia y variaciones concomitantes. 
Hay conceptos, dice Gaos, a los que no corresponde una imagen sensible. Tal ocurre con los espacios de más de tres dimensiones, inimaginables pero pensables. Igualmente con los "objetos metafísicos" (el alma inmortal, el espíritu puro, Dios), que son "perfectamente concebibles" y no imaginables de manera adecuada. Finalmente, la diferencia entre pensamiento e imagen se muestra en los conceptos de imposibles: el cuchillo sin hoja al cual le falta el mango y el hombre sin extremidades al cual le falta el tronco y la cabeza, son dos conceptos contradictorios, son dos imposibles; pero son dos. Su diferencia no se encuentra en su objeto, pues carecen de él, no son indicativos de nada, pero son dos conceptos distintos no por indicación sino por especificación. Las imágenes de estos imposibles son imposibles; los conceptos de imposibles es lo único que cabe dentro de su imposibilidad (p. 193 ss.). Estos dos conceptos de imposibles, como el del círculo cuadrado, no son lo mismo específicamente aunque indicativamente sean lo mismo, dado que no indican nada. Pero si son dos específicamente diversos, es que puedo concebirlos; de lo contrario no serían dos sino uno y mismo imposible. En cambio, no puedo imaginarlos. (Notamos que, si bien los "conceptos metafísicos" y los "conceptos de imposibles" se asemejan por la imposibilidad de ser acompañados por una imagen congruente, son tratados por nuestro autor como dos tipos de conceptos radicalmente diversos.)

Queda también marcada la diferencia entre pensamiento y palabra. No admite la prueba de Husserl, según la cual "le vainqueur du Iéna" y "der Besiegte von Waterloo" son dos expresiones que designan un solo concepto de objeto: Napoleón; siendo por tanto este único objeto de pensamiento distinto de aquellas dos expresiones. Porque para Gaos se trata de dos expresiones, de dos modos distintos de una sola sustancia, distinta ésta también de los modos (p. 189 ss.). ${ }^{5}$ Pero ofrece, a su vez, su propia prueba. La expresión verbal o palabra es la expresión externa de una palabra interior (por esto Gaos afirma que la definición tradicional de mentira está mal formulada: no es decir lo que no se piensa, porque nada se dice al modo humano que no se haya pensado; la definición de mentira debería especificarse como el decir lo que se piensa que no es verdadero, aunque sí se piensa). Pero la palabra interior es una imagen (auditiva si es verbal o visiva si es escrita). Ahora bien, como ya hemos demostrado que el concepto y la imagen son diferentes (p. 193 ss.), el pensamiento es irreductible a la expresión.

Otra prueba ofrecida por Gaos para ilustrar si no demostrar las diferencias entre pensamiento y lenguaje, se refiere a las expresiones negativas: en ellas hay más lenguaje, digámoslo así, que en las correspondientes positivas:

5 En cambio, admite como válida la prueba cuando se refiere al triángulo equiángulo y al triángulo equilátero (ibid.), porque aluden, segun Gaos, modal y sustancialmente al mismo objeto. 
"inexistencia" es equivalente a "existencia más no". En cambio, hay menos objeto. En rigor, en las expresiones negativas no hay objeto; habiendo una realidad de más sonidos gráficos no se objetiva un plus de realidad.

El pensamiento humano, concluirá con razón Gaos, sólo existe expresado verbalmente, siquiera sea con palabra interior; pero no consiste en la expresión verbal, ni siquiera en la palabra interior.

Salvados el empirismo (el pensamiento no es la imagen sensible) y el positivismo lógico (el pensamiento no es el lenguaje), queda el pensamiento libre y desgravado para acceder al ente metafísico. Parece que estamos frente a la razón pura; pero no es así.

\section{Imposibilidad de una teoría pura}

Como contraste, esta apertura metafísica se cierra de nuevo por el hecho de que José Gaos duda y aun rechaza la posibilidad de una teoría pura, libre de las intervenciones del sujeto que la piensa. Una teoría de tal naturaleza es para él una teoría ideal, no real (pp. 276-277); pero un ideal inasequible (pp. 251-252), que constituye incluso una manifestación de la soberbia del hombre y de su afán de divinización (pp. 463-464).

Esta aseveración, según la cual la teoría pura es pura teoría, o teoría de sí misma, se fundamenta en el análisis fenomenológico de las expresiones en cuanto fenómeno humano por excelencia. Las expresiones humanas no son sólo designantes de objetos (si lo fueran, estariamos ante una teoría pura) sino también significantes de emociones y mociones del sujeto que designa a los objetos. Esta carga de significación subjetiva inserta en toda proposición impide una consideración de los objetos indiferente a las emociones y pasiones del que los piensa, y tendrá consecuencias medulares en la cuestión de la existencia de los objetos metafísicos. ${ }^{6}$ Absuelto el pensamiento de la palabra y de la imagen, queda, sin embargo, afectado por los estados de ánimo del sujeto pensante.

Es sabido que la metafísica se caracteriza precisamente como una ciencia que pretende acceder a su objeto sin referencia al sujeto que lo piensa. El conocimiento del ente en cuanto ente, definición clásica de la metafísica, sólo puede pretenderse dentro de la posibilidad de una teoría pura, al menos como meta, asequible o no, a la que podemos acercarnos de manera progresiva y a la que el hombre se dirige con una filía incompatible con aquella confesada y derrotista inasequibilidad.

Por el contrario, José Gaos se muestra enemigo de lo que él llama la teoría clásica de la teoría (es decir, la teoría pura).

${ }^{6}$ Cfr. Del hombre, ed. cit., lecciones 1-VI. 
Es la teoría de la posibilidad de un pensamiento exento de toda influencia de las emociones y mociones sobre él, o sólo la objetivación llevada a cabo por él, o de la posibilidad de objetivar con independencia absoluta de toda emoción y moción.

Es la teoría que equivale a sostener que el desprendimiento del sujeto pensante y objetivante, del resto de su objetividad, puede ser total (p. 276).

La teoría de la posible total objetividad - llamémosla así- es rechazada, como se sabe, por Heidegger, para quien la independencia respecto de la conciencia presupone la conciencia, ${ }^{7}$ y por Ortega: "es preciso que ante las cosas se sitúe un sujeto [...] teorizante para que adquieran la posibilidad de ser o no ser [no ya de ser pensadas o no serlo] [... ] Del mismo modo, una cosa no es igual a otra si no hay, además de ellas, un sujeto que las compara [...] ] así, generalizando [...] el ser o no ser brota de las cosas al choque con la actividad general teorética [...] El ser de los entes [...] carece de sentido si no [... ] cuando un sujeto pensante entra en relación con ellos". 8 Como tal concepción del conocimiento del ser de las cosas no es privativa ni de Ortega ni de Heidegger sino de su común filiación respecto de Husserl, es a éste a quien debemos atribuir la postura de Gaos. ${ }^{9}$

Pero nuestro autor no se limita a rechazar la posibilidad de la clásica teoría pura, puesto que defiende además otra teoría, la de la "motivación" -forma especial de "causación"- de los conceptos metafísicos, morales y estéticos, de las categorías de la razón... por emociones y mociones (ibid.). ${ }^{10}$

7 Cfr. Martín Heidegger, El ser y el tiempo, § 43.

8 José Ortega y Gasset, Obras completas, 1983, vol. IV, p. 56; véase también, vol. VII, p. 141.

9 "Una realidad en sentido estricto y (que fuese) absoluta es exactamente lo mismo que un cuadrado redondo." Edmund Husserl, Ideen I, $\S 55$.

10 Podría objetarse que los argumentos empleados por José Gaos para invalidar la posibilidad de una teoría pura (de pasiones, mociones, emociones, afectos y sentimientos) resultan igualmente válidos para rechazar los de la fenomenología pura, lo que no le impide emprenderla de modo riguroso, paciente y hasta reiterativo, a lo largo de su obra. Pero para Gaos las incidencias más acusadas no ya del sujeto - Husserl, Heidegger, Ortega - sino de los estados de ánimo del sujeto se dan precisamente en las proposiciones metafísicas y, en concreto, en las expresiones negativas, interrogativas e imperativas, originantes de conceptos metafísicos ( $\mathrm{Del}$ hombre, p. 101). Particularmente, la negación tiene un enfático carácter creador (p. 353). La negación verbal, el concepto no, requiere algo más que la presencia de un objeto (p. 355), pues las negaciones no tienen objeto propiamente: ese algo más resulta ser un aspecto clave en la epistemología de nuestro autor y de sus interpretaciones sobre la metafísica y la antropología filosófica. (Digamos ahora solamente que la negación es característica exclusiva del hombre: pp. 349-350 y 354.) 
Todos los objetos que hay

Como corresponde a una fenomenología rigurosa, la obra de Gaos se encuentra llena de inventarios, y de inventarios de los mismos inventarios. La labor ejercida por nuestro filósofo merece el calificativo de enciclopédica. En ella se manifiesta un conocimiento poco común de la historia de la filosofía, entendida como ésta debe - a mi juicio- entenderse: no un elenco de soluciones, sino una secuencia de diversos acercamientos a unos mismos problemas.

El inventario más importante, que constituye, a nuestro parecer, el perno sobre el que gira toda la filosofía de Gaos, es el de lo que él mismo denomina todos los objetos que hay (pp. 96-97) o "todos los fenómenos y objetos que hay":11

a) fenómenos físicos (una piedra volcánica)

b) fenómenos psíquicos (una emoción)

c) fenómenos u objetos ideales (un número o una figura geométrica, un concepto)

d) objetos metafísicos físicos (el átomo, la onda electromagnética)

e) objetos metafísicos psíquicos (el alma, Dios)

A lo largo de la obra, los fenómenos a) y b) guardan una relación (que nunca queda bien discernida, y ello es uno de los puntos de indecisión de Gaos, que luego se advertirá) con los objetos d) y e); es decir, hay cierta correspondencia entre los fenómenos y los objetos metafísicos, y esa correspondencia es justo el problema de la metafísica en cuanto tal.

Los fenómenos u objetos ideales c) constituyen en cierta manera el parteaguas entre los fenómenos a) y b) y los objetos metafísicos d) y e), pues tienen carácter fenoménico, por un lado, y, por otro, poseen características que parecerían propias y exclusivas de los objetos metafísicos, como la ubicuidad y la eternidad.

Una buena parte de la tarea filosófica de Del hombre consiste justamente en precisar la naturaleza o constitutivo propio de "todos los fenómenos y objetos que hay", tarea que nosotros reduciremos aquí con el fin de abordarla sólo en la medida en que sea útil para comprender el tratamiento que da Gaos a las cuestiones metafísicas.

11 “Los perceptos [objetos percibidos], Jas imágenes, las emociones y mociones [apetitos y actos voluntarios], las relaciones, los conceptos, o los fenómenos físicos, psíquicos, ideales y los objetos metafísicos, son todos los objetos que hay" (p. 270).

El tema de todos los objetos que hay goza de las preferencias de nuestro autor, y es asunto recurrente en su investigación. El punto de arranque de esta preocupación podría encontrarse quizá en las Lecciones de teoría de los objetos, en La filosofia y la universidad, UNAM, 1958. 
Diferencia y relación entre los fenómenos y los objetos metafísicos

Para Gaos la diferencia entre el fenómeno y el objeto metafísico no sólo es indiscutible, sino definitoria (pp. 119-120 y 288-289). Esta diferencia reside exactamente en que el fenómeno, por definición, está presente para el sujeto que lo conoce, en tanto que el objeto metafísico se define no sólo por no estar presente, sino por su imposibilidad de estarlo (p. 123). El objeto metafísico, por definicion, no puede nunca ser fenómeno ( $c f r$. pp. 339-341). Esta caracterización de lo metafísico como lo que no puede estar presente para el sujeto que lo conoce hace que Gaos difiera de todo antecedente filosófico, que sepamos. Suele considerarse lo meta-físico como lo no sensible, o lo no material, o lo no accidental, o lo psíquico, o lo espiritual, o lo trascendente, etc. La diferencia con estos antecedentes se hace notoria cuando, por ella, Gaos llama meta-físico a lo que todos hemos llamado siempre físico, entrando en la paradoja (sólo verbal) de que haya objetos metafísicos físicos, además de objetos metafísicos psíquicos. En efecto, cuando determinadas ciencias, como la física, tratan de objetos que no son susceptibles de convertirse en fenómenos, como el átomo o la onda electromagnética, "hacen en realidad metafísica" (pp. 182-185).

Esta tajante división entre lo fenoménico y lo metafísico contrasta con la relatividad del criterio que la establece, es decir, el yo pensante. ¿Cómo sabemos si una estrella hoy no presente para el hombre lo será alguna vez para éste? El criterio de Gaos para discernir el fenómeno por un lado y el objeto metafísico por otro es, ya de por sí, un criterio subjetivo, y por consiguiente problemático, con una problematicidad que aparecerá en otras secuencias de este estudio. Si, para usar un ejemplo suyo, el átomo es un objeto metafísico, ¿dejará de serlo cuando un futuro instrumental científico lo transforme en observable, como ahora lo es su huella en la cámara de Wilson? ¿Dejaría el electrón de ser objeto metafisico si lográramos precisar su posición y su velocidad como ahora es posible hacerlo alternativamente para la una o para la otra? ¿Es el carácter metafísico de un objeto algo dependiente del estado de la ciencia?

En este mismo ámbito de la física, la abrupta diferencia establecida entre el fenómeno y el objeto metafísico se mantiene implacablemente. Recogemos otra vez uno de los diálogos en el seminario cuyo contenido es la obra que estudiamos: "-la atomística de nuestros días ha reducido efectivamente todos los elementos al hidrógeno. -Sí, metafísicamente. Fenomenológicamente el plomo sigue sin ser oro, como prueba la más científica de las ciencias humanas, la economía" (p. 171).

Parte de esta problematicidad se encuentra ya en el establecimiento de las relaciones entre uno y otro ámbito. Aunque Gaos atisba en alguna ocasión que el objeto metafísico pueda ser sustancia del fenómeno, abandona 
pronto esta consideración, para centrar el nexo fenómeno-objeto metafísico en la sola relación de causalidad (p. 122). No se crea, sin embargo, que el problema de la relación causal objeto metafísico-fenómeno se refiera al de la relación entre el alma y el cuerpo: esta relación, para él, es una relación entre fenómeno psíquico y fenómeno físico (p. 181), no entre lo metafísico y lo fenoménico. Porque la diferencia (y relaciones) entre los fenómenos psíquicos y los fenómenos físicos es a su vez fenoménica (p. 170). En cambio, Gaos parece seguro de que la causalidad, de darse realmente, sería metafenoménica (p. 304), y la que pueda darse entre el objeto metafísico y el fenómeno tiene en el un tinte irrecusablemente kantiano: la causalidad resulta indudable como concepto (es indudable que poseemos el concepto de causalidad); en cuanto concepto es fenómeno, pues nos está presente; pero si la causalidad implica "un verdadero producir" entonces ya no es fenómeno sino objeto metafísico (pp. 311-314), y -agregamos nosotros-si la relación entre lo fenoménico y lo metafísico es problemática, la causalidad, en su carácter de objeto metafísico, no podrá resolvernos el problema de la relación entre lo fenoménico y lo metafísico, aunque el mundo metafísico se interprete como "fábrica de los fenómenos" (pp. 182-183). ${ }^{12}$

Gaos no sospecha, al parecer, la posibilidad de que el ser metafísico se manifieste, se torne apofántico, se patentice no por sí mismo sino precisamente por medio del fenómeno, como la sustancia se muestra por medio de los accidentes, la naturaleza trasparece en las operaciones o la causa se hace notoria por sus efectos. Al revés, emplea la expresión heracliteana contraria: los seres metafísicos se encueniran escondidos detrás de los fenómenos (y la causalidad, único posible nexo entre ambos mundos, se encontrará escondida también, a fuer de metafísica).

\section{Objetos ideales y entes metafísicos}

Uno de los más acusados aciertos de José Gaos es la manera de distinguir entre objeto ideal y objeto metafísico (p. 113), asunto en el que la filosofía moderna se encuentra indudablemente enredada. La diferencia básica reside en que el objeto ideal es coincidente con su concepto, en tanto que el objeto metafísico - para serlo- debe ser diferente de él (el concepto de Dios es fenoménico - nos está presente-, pero la realidad de Dios sería metafísica, p. 108). La diferencia que hay entre un objeto ideal y un objeto metafísico es la que habria, por ejemplo, entre los números y las figuras geométricas, por un lado, y el alma inmortal, por el otro (p. 106). Aquí la

12 Téngase en cuenta que, para Gaos, la causa eficiente es la única causa que modernamente puede considerarse como tal, aunque en su obra se encuentran interesantes referencias a la causalidad formal, en las que ahora no podemos detenernos. 
posición de Gaos es también tajante, diferenciando de manera radical el objeto ideal y el objeto metafísico, y ello aunque los objetos ideales tengan caracteres parecidos a los metafísicos (p. 477), pues los conceptos u objetos ideales son, como los objetos metafísicos mismos, ubicuos y eternos (pp. 386-387). Incluso, en algún momento, Gaos dice que los objetos ideales trascienden el mundo fenoménico y el mundo metafísico, pues tienen valor en ambos. Por ello nosotros los hemos calificado antes de parteaguas, como pertenecientes a ambas laderas de los fenómenos $\mathrm{y} / \mathrm{u}$ objetos que hay. Gaos dirá gráficamente que la proposición "dos más dos suman cuatro" ha de ser verdad en el cielo y en el infierno, como lo es aquí.

Esta diferencia entre lo ideal y lo metafísico (tan profunda al menos como entre lo metafísico y lo fenoménico) puede también ilustrarse del modo que sigue: "Los objetos o existentes matemáticos se han tomado por objetos ideales arquetípicos" (p. 296), por un lado; por otro: los objetos metafísicos ejemplificados por Gaos - arquetípicos por tanto de éstos, como los matemáticos lo fueron de aquéllos-son: el átomo, el alma y Dios (p. 131). ¿Qué son, entonces, los objetos ideales? Son definidos así: "conceptos pensables de objetos inconcebibles como distintos de los conceptos mismos" (p. 196). El concepto cuatro sería un concepto pensable con un objeto - cuatro-que no puede ser distinto del concepto cuatro mismo: no hay un cuatro objetivo comprendido por el concepto cuatro y distinto de este concepto.

En el caso de que estuviéramos ante cuatro mesas, lo objetivo, distinto de su concepto, serían las mesas mismas, pero no una realidad que diéramos en llamar cuatro, y que sería sólo una cantidad mental. En cambio, Dios y el espíritu puro son pensables (p. 196), pero como conceptos cuyo objeto puede ser distinto de su concepto, dejando en suspenso ahora, si para Gaos lo es realmente o no (pero si el objeto Dios no fuera distinto de su concepto, no sería propiamente un objeto metafísico, sino algo similar a un fenómeno u objeto ideal, como cuatro).

Decimos algo similar a un objeto ideal porque, según nuestra interpretacion del pensamiento de Gaos, las afirmaciones que acabamos de hacer pretenden simplificar un estado de cosas más complejo. Aun en el caso de que al concepto Dios no le correspondiera un objeto distinto de su concepto - esto es, un ente con existencia independiente de la de su concepto-, aun en ese caso el concepto Dios se dintinguiria, como objeto metafísico que presuntamente es, del concepto cuatro, como objeto ideal que es. En efecto, el concepto Dios es pensable de tal manera que su concepto se refiera a un ente distinto del concepto mismo; mientras que cuatro no es pensable de esa manera, sino de la contraria: es un concepto cuyo objeto no puede ser un ente distinto del mismo concepto. El concepto metafísico, y su correspondiente objeto o contenido, aun cuando no les correspondiera un ente 
existente fuera del concepto, es pensable como si pudiera corresponder a un ente tal.

De ahi que, para deshacer un posible equivoco, nosotros hemos preferido llamar ente metafísico a lo que Gaos denomina objeto metafísico, pues siendo éste indudablemente objeto - si no, no sería pensable - no lo es de la misma manera que lo es el objeto ideal, al que le concierne no el ser sino el mero ser objeto de pensamiento: sería objeto puro. ${ }^{13}$

Del concepto metafísico puede dudarse si es o no un concepto con un ente o existente propio que le corresponda. Pero esta duda no cabe ni en el caso del concepto del objeto ideal (que carece de ente correspondiente) ni en el caso de los conceptos negativos, que no tienen ni siquiera objeto propio (p. 418). Añadimos nosotros que es imposible pensar que cuatro exista, o que exista una realidad directamente correlativa del concepto no, mientras que no sólo es posible pensar que Dios existe, sino que, conforme a la versión spinoziana del argumento ontológico, es imposible pensar que Dios no existe (lo cual, pese a Spinoza, no demuestra que exista).

Apelando a categorías escolásticas, hoy por desgracia olvidadas, los conceptos de objetos ideales de Gaos se comportarían, respecto de la posible existencia de esos objetos, no ya de un modo negativo (no considerándola) ${ }^{14}$ sino privativo (rechazándola o imposibilitándola). En tanto que los conceptos metafísicos se comportarían al menos de un modo permisivo (pudiendo sus objetos existir como entes independientes de sus conceptos). ${ }^{15}$

Pero para explicar la naturaleza del concepto metafísico parece que Gaos nos pediría arbitrar una categoría conceptual más: no ya negativa o privativa (que implicaría el olvido o el rechazo, respectivamente, de la metafísica) ni siquiera permisiva (agnóstica respecto a ella), sino una relación con

13 Antonio Millán Puelles, Teoría del objeto puro, Rialp, Madrid, 1990.

14 Esta no consideración de la existencia real de los objetos se aproximaría a la actitud fenomenológica de Husserl (abstenerse de toda afirmación y negación - y hasta de toda dudaacerca del valor existente de los objetos), tal como se encuentra en Ideen I, $\S 38$. Aunque este puro abstenerse de "todo juicio sobre las existencias" tenga en Husserl también una raíz vitalista ("soy plenamente libre de hacerlo"), no es la actitud de Gaos - y ello lo hace completamente original- respecto de los objetos ideales, cuya existencia real se torna imposible, ni respecto de los objetos metafisicos sobre cuya existencia real se indaga teoréticamente porque inquieta vitalmente.

15 La situación negativa, privativa y permisiva de los conceptos, y especialmente esta última, puede encontrarse en Juan de Santo Tomás, Cursus Theologicus, t. I (In Iam, Quæstiones I-VIII, Disputatio VI, art. III, Ludovicus Vives, París, 1883, nn. XX y XXVII, pp. 678-684). Respecto de la posibilidad de pensar los conceptos de objetos sin referirse o refiriéndose a la existencia, Tomás de Aquino, Expositio De Trinitate de Boecio, q.5, a.3, donde se distingue el concepto metafísico del concepto matemático. Y, en su inicio, cfr. Aristóteles, Metafísica VI, 1, 1025b 16-17: hay ciencias que "nada dicen acerca de si existe o no existe el objeto de que tratan". 
la existencia real de sus objetos, que podríamos llamar exigitiva: pues el átomo, el alma inmortal y Dios son conceptos de entes cuya existencia es exigida para explicar la existencia de fenómenos tales como las combinaciones químicas, la identidad del yo y el ser de lo contingente.

Conviene advertir que esta dimensión exigitiva de los conceptos metafísicos respecto de la existencia de los entes que pretenden conceptualizar, se encuentra en Gaos muy distante de la exigencia de existencia que Leibniz incluye en los conceptos de los entes posibles. ${ }^{16}$ Leibniz se traslada abusivamente de la posibilidad de existencia a la exigencia de existencia, hasta el grado de que los mundos posibles tendrían una pretensión de existir semejante a la del mundo efectivamente existente. ${ }^{17}$ En Gaos, el carácter exigitivo - llamémoslo así- de la existencia por parte de los entes metafísicos no provendría de una aptitud para existir encontrada en los conceptos mismos (aptitud que no se encuentra en los conceptos de objetos ideales) sino de la exigencia vital y, de alguna manera, además, teorética, de dar razón de la existencia de fenómenos existentes, la cual no podría explicarse si aquéllos, a su vez, no existieran.

Hay, pues, un paso de mayor cercanía del concepto metafísico a la existencia de su objeto. Pero tal exigencia de existencia no es demostrativa de ésta. La exigencia de existencia de los objetos metafísicos psíquicos (el alma inmortal y Dios) es además requerida por instancias vitales, nota característica para Gaos, aunque tampoco, aún con más motivo, posean para él capacidad teorética de demostración. Lo mismo — diremos analógicamente- que la exigencia del hombre para llegar a un estado feliz no demuestra que habrá de llegar a la plenitud de ese estado, o como la exigencia vital de la bellota no garantiza que llegará a la condición de encina.

\section{A. Características de los objetos ideales}

Independientemente de ello, el mérito de Gaos es haber hecho un valioso análisis de las notas constitutivas del objeto ideal (pp. 117-122) y de las que constituyen el objeto o ente metafísico (pp. 122-123), que implica a nuestro parecer la máxima clarificación a los graves problemas suscitados en la historia de la filosofía al intentar distinguir estos dos tipos de conceptos.

16 “Omne possibile exigit existere." De veritatibus primis, ed. Erdmann, p. 99.

17 "Une infinité d'autres mondes étant également possibles et également prétendant à l'existence." Essai de théodicée, parte I, $\S 7$. En estas observaciones tenemos en cuenta, sin embargo, que Leibniz es mencionado por Bernabé Navarro entre "las influencias importantes y cercanas" recibidas por Gaos en sus dos últimas obras. (Cfr. Bernabé Navarro, "El pensamiento griego en la obra de José Gaos", en Obras completas de José Gaos, UNAM, México, 1991, t. 2, p. 33.) 
1) Para la determinación del carácter extenso de los números y las figuras (objetos ideales, como dijimos, arquetípicos, pp. 198-199), nuestro autor hace una comparación con el que corresponde a los fenómenos físicos: éstos tienen una extensión determinada por relación con otros fenómenos físicos, tomados como unidades de medida. "Esta hoja en que estoy leyendo tiene $28 \times 22 \mathrm{~cm}$." En cambio, el rectángulo geométrico -euclideano-, como objeto ideal que es, no posee otra extensión que la relativa a sus propias partes internas, como la que corresponde a su área, que es igual al producto de la base por la altura. Los fenómenos físicos rectangulares poseen unas longitudes determinadas medibles, longitudes concretas o reales de su base y su altura por relacion con unidades tomadas de otros fenómenos. Esta diferencia es, para nosotros, muy ilustrativa de la diversa constitución que poseen el fenómeno físico real y el fenómeno o concepto $u$ objeto ideal.

2) Los números y figuras —objetos ideales arquetípicos - no se localizan en ningún lugar determinado: "el uno y el rectángulo están localizados en todo lugar. En este sentido, los números y figuras poseen una peculiar ubicuidad pareja a su peculiar inextensión de la que deriva su peculiar inespacialidad" (nótese que así como la característica anterior separa el objeto ideal del fenómeno físico, ésta - y la que analizaremos seguidamente- lo aproxima al objeto metafísico que también se encuentra separado-joristón, diría Aristóteles- del fenómeno físico).

3) Algo similar ocurre con los objetos ideales (números y figuras) en su relación con el tiempo, a diferencia de la relación que guardan con éste los fenómenos psíquicos (un sentimiento, una emoción) y los fenómenos físicos (una tormenta): los objetos ideales "no tienen lugar, ni figuradamente, en tal o cual 'espacio' de tiempo, sino simultáneamente y sucesivamente en todos". Poseen, por tanto, una peculiar intemporalidad.

4) Los números y las figuras, como prototipos de objetos ideales, no poseen cualidades sensibles. "Es por lo que ninguna Aritmética ni Geometría contienen un capítulo sobre el color de los números o de las figuras [... o o sobre su dureza o blandura."

5) Los objetos ideales no son objeto de la percepción (no son perceptos, en la terminología de Gaos), sino "imperceptibles", ni podemos tener de ellos la conciencia que cada uno posee de sus estados y movimientos de ánimo como acontece no ya sólo con las emociones sino con las percepciones mismas de los objetos sensibles: "nadie percibe número y figura como algo suyo".

6) Pero la característica más notable de los números y figuras parece ser la de su peculiar "intersubjetividad": "mientras que la de los perceptos y los fenómenos psíquicos apenas es 'parcial', la de los números y figuras es 'total'. Los números y figuras son objetivados por todos los sujetos simultáneos y 
subjetivos. La intersubjetividad de los números y figuras 'trasciende' del mundo de los fenómenos al de los objetos metafísicos [...] Esto es algo absolutamente único: mientras que los demás fenómenos, físicos y psíquicos, están confinados, por decirlo así, en sus respectivos mundos, un color no puede ser onda electromagnética o el alma sustancial no puede ser fenómeno. Los números y figuras son así un singular vínculo entre fenómenos y objetos metafísicos." El énfasis en este singular vínculo constituido por el objeto ideal que abraza lo fenoménico y lo metafísico no sirve a Gaos - y esto debe ser notado- para el paso o verdadero trascender del fenómeno al ámbito metafísico; al contrario, es un vínculo que, en cierto modo, hace problemático ese paso, ya que la problemática se ceñirá a este justo y preciso punto: al trascender el fenómeno, ¿accederemos a un objeto ideal o a un objeto metafísico? No son pocas las (presuntas) metafísicas racionalistas que suponen tener acceso a entes metafísicos cuando sólo se encuentran en relación noética con meros objetos ideales: una grave confusión entre la metafísica y la matemática, ya señalada en la Crítica de la razón pura.

En este sentido, la distinción entre objetos ideales y entes metafísicos por parte del filósofo hispano-mexicano constituye una - hasta entoncesmuy necesaria aclaración de los ya profundos atisbos de la escolástica, que distinguían dos maneras de conceptualizar: la que mira el contenido nocional y la que mira el ser mismo de la cosa, vale decir, el ser de la cosa independientemente de sus condiciones conceptuales. ${ }^{18}$

7) Al no ser perceptos ni fenómenos psíquicos —estados de ánimo-, la foma del eidein de los objetos ideales, la manera de verlos y objetivarlos ha de ser, consecuentemente, peculiar y propia.

8) Finalmente, los números y figuras no están ni entre sí ni con los demás objetos en relaciones de causalidad ni de finalidad (lo cual ya había sido señalado, añadimos nosotros, por Aristóteles - Metafísica III, 2, 996a - en donde enuncia que las matemáticas nada dicen de lo bueno y de lo malo, por carecer de finalidad; y por Tomás de Aquino - S. Th. I, 44, 1, ad 3-, cuando asegura que en las matemáticas nada se razona por causa eficiente).

Estas ocho características han conducido, afirma Gaos, a muchos filósofos desde Platón hasta Husserl -pasando por los defensores del "realismo" en la disputa medieval de los universales-, a concebir los números y las figuras "como una clase de objetos distinta de las demás clases de objetos".

De esto, añade, no tiene la menor noción el hombre ingenuo. Incluso los más grandes matemáticos, en cuanto puramente matemáticos, son, en este sentido, meros hombres ingenuos. 


\section{B. Características de los entes metafísicos}

1. Los objetos metafísicos físicos -átomos, ondas electromagnéticas, partículas elementales - como los fenómenos físicos mismos, y a diferencia de los objetos ideales extensos - con esa extensión proporcional interna de la que acabamos de hablar-, son espaciales.

2. Los objetos metafísicos físicos y psíquicos, también a diferencia de los objetos ideales, son temporales (como el átomo o el alma sustancial) o intemporales (como Dios).

3. Se encuentran respecto de los fenómenos en una relación de causalidad que se denomina - con denominación única en Del hombre-como relación singularísima: los objetos metafísicos físicos causan los fenómenos físicos; y los objetos metafísicos psíquicos causan los fenómenos psíquicos. (Recordemos, sin embargo, que la causalidad metafísica entraña en el pensamiento de nuestro autor problemas especiales, como ya se advirtió al hablar de las relaciones entre los fenómenos y los entes metafísicos. A pesar de ello, los entes metafísicos pueden ser concebidos como capacitados para el ejercicio de acciones causales, mientras que nadie concebiría, excepto Platón, los objetos ideales con tal capacidad, de manera que el paradigma de un triángulo rectángulo produjera formas rectangulares reales.)

4. No sólo hay una relación con los fenómenos en la línea de la causalidad eficiente, sino también en la línea de la sustancialidad: los objetos metafísicos sustentan, soportan los fenómenos físicos. Pero, como ya advertimos, esta sustentación no ofrece la posibilidad de que lo sustancial se manifieste en lo fenoménico, sino al revés, se oculta debajo de ello, de manera casi kantiana. Los fenómenos, entonces, no son la manifestación de algo sustancial o en sí, sino que lo son sólo de sí mismos, en una fenomenicidad reduplicada o tautológica que es uno de los supuestos más importantes, aunque quizá inadvertido, latente en la fenomenología de Gaos.

5. Al igual que los objetos ideales, los objetos metafísicos no tienen tampoco cualidades sensibles, aunque tengan número. Esto último precisaría, a nuestro parecer, una aclaración que nos atrevemos a presentar a título de interpretación personal: ha de haber un número preciso de átomos -objetos metafísicos físicos- en el universo, aunque lo desconozcamos, asumiendo la hipótesis de un universo finito; y ha de haber un número determinado de espíritus puros, asumiendo la hipótesis de que los haya. Pero, asumiendo estas hipótesis, la pregunta ¿cuántos triángulos rectángulos hay en el universo?, carece de sentido, mientras que posee sentido la pregunta acerca del número de átomos o de espíritus puros, bien que no se pueda contestar a ella. 
6. Los objetos metafísicos psíquicos (Dios y el alma sustancial) pueden concebirse como si tuvieran conciencia de sí mismos, lo cual es inconcebible en los objetos ideales: el triángulo y la esfera carecen de autoconciencia.

7. Los objetos metafísicos no nos están presentes, no son fenómenos, mientras que los números y las figuras sí. La cuestión acerca de cómo conocemos los objetos metafísicos, no estando presentes, por carácter propio, es precisamente el eje del problema metafísico en Gaos, ante el que se encuentra, a la par, inquieto e irresoluto.

Objetos ideales y entes metafísicos: posición, diferencia y duda

No obstante lo anterior, Gaos consigna, respecto de los objetos ideales, que, en la historia de la filosofía, "se los ha concebido ya como conceptos, ya como esencias $u$ objetos, en general, distintos de los conceptos. Es lo hecho por Husserl que los distingue, llamándolos 'esencias matemáticas', de las además llamadas por él 'esencias morfológicas'" (p. 296). Y es que la "inespacialidad e intemporalidad anejas a la identidad intersubjetiva de los conceptos [cuando alguien dice cuatro, todos pensamos idénticamente el mismo concepto], las corrobora la peculiar trascendencia metafísica de éstos" (p. 303). Sin embargo, Gaos ha subrayado acertada y pacientemente la diferencia entre lo metafisico y lo ideal, que hoy, decimos, se encuentra emborronada, siendo esto último origen de falsas concepciones respecto de la metafísica como ciencia. En nuestro autor lo ideal y lo metafísico son profundamente diversos, a pesar de su aparente proximidad.

Esta proximidad entre el objeto ideal y el objeto metafísico viene dada, a juicio de Gaos, por el hecho original, muy oportunamente señalado por él, de que los conceptos u objetos ideales no son fenómenos psíquicos. Si lo fueran "habría que concebirlos como modos [accidentes] [...] de las sustancias psíquicas, de las psiques, de los sujetos. Siendo objetos existentes en el sentido precisado, pueden concebirse como sustancia, con tal de no concebirlas, inconsecuentemente, como sustancias físicas ni psíquicas: su sustancialidad consistirá rigurosamente en no ser modos - accidentes-de ninguna sustancia, ni psíquica, ni siquiera de su mismo género, ni ideal; sino ser, por ende, cada uno de ellos pura y simplemente en sí."

"La concepción de los conceptos como tales objetos ideales representa, sin duda, una concepcion de lo existente que sorprende por extraña a la corriente [...]: los pensamientos no son fenómenos psíquicos [...]; la sorpresa debe desaparecer en cuanto el sorprendido se percate, como puede hacerlo, de que salva los fenómenos mejor que la corriente, por no ser sino el resultado mismo de una fenomenología más acuciosa y rigurosa" (p. 306). 
La interpretación de este importante texto nos llevaría más lejos. No hay duda de que el objeto ideal no es un mero accidente de la sustancia del que lo piensa; si así fuera, constituiría un quid unum, o mejor, un quid alterum con la sustancia de la que sería modalidad accidental: se subjetivizaría por su relación hilemórfica con ella, y perdería la objetividad que le compete como ideal (con su intersubjetividad, ubicuidad $\mathrm{e}$ intemporalidad anejas). Pero los objetos ideales tampoco son a su vez accidentes de otras sustancias, sino que serían sustancias de sí mismos, dado que no son modos o accidentes ni de quien los piensa ni de los supuestos entes pensados: pero no sustancias físicas o psíquicas, sino, justamente, sustancias ideales.

No es nuestro asunto ahora la investigación de la naturaleza del objeto ideal, que sería, según parece, puro objeto, sin más referencia al sujeto pensante que el hecho mismo de ser pensado, y sin otra referencia respecto de la realidad que su carácter intersubjetivo no correspondiente a una realidad propia como tal - sustancia psíquica o figura. Debemos limitarnos a señalar que si por un imposible al objeto ideal —con su intersubjetividad, ubicuidad e intemporalidad anejas - correspondiese una sustancia física o psíquica que fuera representada por él, como su concepto, nos hallaríamos, precisamente, ante un ser metafísico. El que se den sustancias ideales, pues, como conceptos, nada dirá ni dejará de decir respecto a los existentes metafísicos (físicos o psíquicos). Los objetos ideales son fenómenos; los existentes metafísicos, por definición, no.

\section{Metafísica del hombre}

Estas averiguaciones distan mucho de ser puramente técnicas, o aun cripticas, dentro del cerrado ámbito de las relaciones entre dos métodos filosóficos: el de la fenomenología y el de la metafísica. Aunque nuestro autor desea ceñirse al estricto ámbito fenomenológico, ya hemos dejado ver que su interés vital es mucho más ambicioso, con lo que no hace sino confirmar sus mismos postulados epistémicos, según los cuales el interés vital supera el marco de la teoría.

En concreto, sus análisis de los objetos ideales y los entes metafísicos le sirven para penetrar en lo que podría llamarse metafísica del hombre o, para decirlo de una manera más fiel a nuestro autor, fenomenología humana; en cualquier caso, en su esencia.

En el análisis de las artes útiles del hombre (lección XXXIX), pone al descubierto la aceleración de la existencia humana, a la que sirven y propician los artefactos suyos, que se producen con vistas a esa aceleración, sintomática de su propia raíz vital: el hombre se encuentra insatisfecho en medio de sus satisfacciones; de ahí su infatigable pasar de unas a otras, en busca de una felicidad infinita que no le es dada de un golpe, sino, en el 
mejor de los casos, en forma transeúnte, sucesiva... y por ello acelerada. Diríamos nosotros que, impedido para alcanzar una satisfacción infinita, la sed de infinitud del hombre pretende apaciguarse mediante una serie infinita de satisfacciones. ${ }^{19}$

Este movimiento acelerado, fruto de una concepción "temporalista" (p. 532), se vincula con la emocional y mocional conciencia de la fugacidad de las cosas, primordialmente las humanas (ibid.). La conciencia de fugacidad tiene dos traducciones vitales: por un lado, ese continuo devenir de las satisfacciones, la insaciable búsqueda de satisfacciones nuevas y distintas (particularmente manifiesta en el modo de vida contemporáneo); pero, por otro, la apelación contra ella, contra la fugacidad, acudiendo a "una vida y Dios eternos en la religión y en la filosofía" (ibid.), al punto de suponer que "no hay un mal mayor que la fugacidad de la existencia o inexistencia, ni bien mayor que la existencia infinita" (ibid.). ${ }^{20}$

Aparece aquí lo que podriamos llamar la definición esencial del hombre por parte de Gaos. Al menos se trata de la descripción humana que, sin atemperamientos, nuestro autor nos presenta en la forma sintáctica única de la definición: "el hombre es el existente consistente en el movimiento real alterno de insatisfacciones y satisfacciones, a medias malo, a un estado ideal de satisfacción infinita, entitativa y existentemente, o puramente bueno" (p. 523).

Se reserva su juicio respecto de la verdadera realidad de ese estado ideal hacia el que el hombre alternativamente se mueve. Lo único que se aventura a proponer es que el ser humano posee ese movimiento, y que le es esencial si es que no es su misma esencia.

Esta postura metafísicamente aséptica está lejos de ser, sin embargo, inflexible y definitiva. Habrá de decirse, por el contrario, que para Gaos la aspiración a la felicidad existencial y entitativamente infinita no es por lo menos una mera ilusión. El hombre es susceptible de ilusionarse de dos ma-

19 La importancia de la velocidad o aceleramiento, "característica de nuestros días" es tema al que Gaos ha prestado reiterada atención: "la velocidad siempre creciente acaba por realizar su más perfecto contra sentido. Se trata de ganar tiempo. Pero a fuerza de ganarlo, mediante la aceleración creciente, se acaba por no hacer más que perder el tiempo [... ] La facilitación cada vez mayor del desplazamiento hace que el mero desplazarse reemplace cada vez más a todo tomar plaza" (José Gaos, "Orígenes de la filosofía y su historia", en Obras Completas, UNAM, 1991, t. 2, p. 73). Lo que aquí se dice del lugar o plaza, en Del hombre se refiere, casi idénticamente, a la satisfacción y al pasar aceleradamente de una a otra, que sustituye a la satisfacción en sí misma, como el desplazamiento a la plaza.

20 Nuestro autor tiene muy presente a lo largo de sus extensos escritos el afán de inmortalidad del ser humano. En Del hombre lo hace tema de su especulación filosófica reiteradamente. Pero esta "universal tendencia a perseverar en el ser", como la denomina en Origenes de la filosofía y su historia (ed. cit. p. 82), no es sólo una instancia puramente metafísica sino también vitalmente antropológica, no ajena al "general egoísmo humano" (ibid.). 
neras: la de "hacerse ilusiones", en donde las ilusiones son engañosas, o la de "tener ilusiones", en la que las ilusiones son ideales (p. 521). Las ilusiones ideales no son, pues, sin más, engañosas. Pero que no sean engañosas no significa que sean, sin más, reales. Lo que sí asegura es que "los ideales son esenciales a la característica fundamental de la naturaleza humana" (ibid.). $Y$ es una característica moralmente necesaria: "el hombre necesita de los ideales [... ] para que tiren de él hacia arriba, de la animalidad hacia la divinidad" (ibid.). Lo contrario sería contentarse con la realidad "fementida", deficiente, insatisfecha, como "'se contentan con su suerte' los seres infrahumanos, achatados a su nivel" (ibid.).

La oscilación entre la insatisfacción real en la que el hombre se encuentra y la satisfacción ideal a la que aspira proviene de lo que Gaos denomina desnivel "onto-axiológico", lo que le hace afirmar: "es el hombre un desequilibrado" (p. 527-528). El problema de la realidad de los entes metafísicos (si son entes o nada más objetos de pensamiento) se trasmina así al problema de la realidad de los valores (si nada más son objetos ideales a los que no corresponde entidad real alguna).

Gaos nos ha ofrecido, como hemos visto, un claro discernimiento entre los objetos ideales y los entes metafísicos, de manera que no caben aquí confusiones ni concepciones neutras (aunque quepan, sí, posiciones neutrales). Pero no sabemos, de la mano de Gaos, si a estos ideales concebidos por el hombre corresponden sólo objetos ideales que coinciden con sus meros conceptos o corresponden entes metafísicos, diferentes de los conceptos mismos, es decir, reales. Quien ha distinguido clara, acuciosa y rigurosamente entre unos y otros gracias a su método fenomenológico, no nos dice - precisamente por su método- si los supremos ideales humanos pertenecen al reino de los primeros o de los segundos, y ello tiene una importante repercusión no ya metafísica sino antropológica, pues no puede resolverse el desequilibrio del hombre, quien se encuentra a la vez sometido a una realidad insatisfactoria, por no satisfacerlo plenamente, y a una idealidad intramundanamente inalcanzable; desequilibrio que mantendrá su vigencia mientras no pueda juzgar si el ideal al que aspira es realizable —como dirá Chesterton del buen idealista- o si simplemente ha idealizado la realidad - como lo dirá del idealista equivocado.

Aun cuando deje en suspenso si las nobles aspiraciones humanas tienden hacia un objeto ideal o hacia un ente metafísico, la posicion antropológica en Gaos es radicalmente distinta de la de Ludwig Feuerbach con la que superficialmente podría confundírsela. No sólo porque Feuerbach asegura que en su aspiración metafísica humana el hombre desvaría (o se enajena), lo cual en modo alguno es afirmado por Gaos, sino porque en Feuerbach las aspiraciones metafísicas del hombre le sirven para contentarse con la 
presente mediocridad, mientras que en Gaos son una rebelión vital contra ella, por deficiente y fementida.

La postura de Gaos, más vitalista que agnóstica, pone otra vez en cuestión la apremiante contemporaneidad de la metafísica. ${ }^{21}$

21 No en vano José Gaos vislumbra en sus Orígenes que "la Historia de la filosofía, debe tener la plenitud de una filosofía plena, una metafísica debe acabarla". José Gaos, Orígenes de la filosofia y de su historia, ed. cit., p. 125. 